\title{
A Disciplina Didática da Matemática nos cursos de Licenciatura em Matemática a Distância: o que apresentam os documentos destes cursos
}

\author{
Claudia Maria Witt ${ }^{1}$ \\ Universidade Federal do Paraná (UFPR), Setor de Ciências Exatas, Programa de Pós- \\ Graduação em Educação em Ciências e em Matemática, Curitiba, Paraná, Brasil \\ Maria Lucia Panossian² \\ Universidade Tecnológica Federal do Paraná (UTFPR), Departamento de Matemática, \\ Curitiba, Paraná, Brasil
}

\begin{abstract}
Resumo
O estudo aqui apresentado objetivou identificar quais aspectos teóricos, práticos, conteúdos e forma são considerados na disciplina Didática da Matemática nos cursos de Licenciatura em Matemática a Distância. Para alcançá-lo, realizou-se pesquisa documental a partir dos dados obtidos no sítio do Ministério da Educação. Identificou-se a existência de 44 cursos nesta modalidade de ensino, possibilitando a coleta de 19 Planos Pedagógicos de Curso e 26 Matrizes Curriculares. A análise das Matrizes permitiu identificar a disciplina Didática da Matemática em 08 destes cursos e foram coletadas as Ementas da disciplina. A análise realizou-se considerando os pares dialéticos teoria-prática e conteúdo-forma e revelou que a disciplina Didática da Matemática assume enfoque teórico, que a prática adotada pode ser reconhecida pelo movimento no sentido de criar, planejar, realizar, gerir e avaliar situações didáticas para o ensino da matemática, dentre outras. Em relação aos conteúdos programáticos, identifica-se a abordagem de parte dos conhecimentos que a didática da matemática como ciência pode possibilitar. Para desenvolvê-los, adota, de modo geral, forma expositiva nas aulas. Alguns destes cursos pretendem a formação para pesquisador em educação matemática. $O$ estudo revelou a necessidade de fomentar discussões sobre a importância da disciplina para a formação inicial de professores.
\end{abstract}

Palavras-chave: Didática da Matemática; Licenciatura em Matemática a Distância; Análise documental.

\footnotetext{
Submetido em: $13 / 12 / 2020$

Aceito em: 17/03/2021

Publicado em: 27/03/2021

${ }^{1}$ Doutoranda em Educação em Ciências e em Matemática pela Universidade Federal do Paraná. Programa de PósGraduação em Educação em Ciências e em Matemática. E-mail: claudiamariaw@gmail.com.

${ }^{2}$ Doutora em Educação pela Universidade de São Paulo. Professora do Programa de Pós-Graduação em Formação Científica, Educacional e Tecnológica da Universidade Tecnológica Federal do Paraná. E-mail: mlpanossian@utfpr.edu.br.
} 


\title{
The Didactic Discipline of Mathematics in Distance Learning Mathematics courses: what the documents of these courses present
}

\begin{abstract}
This present study focuses identify which theoretical and practical aspects and which contents and forms are considered in the discipline of Didactic of Mathematics in the Distance Learning Degree in Mathematics. To reach them, a documental research has made with collected data from the site of Ministry Education. It has been identified the presence of 44 courses in this category of education, which has been made possible to collect 19 Pedagogical Plans of Course and 26 Curriculum Matrices. The analysis of those Matrices has permitted to identify the discipline Didactic of Mathematics in 08 of them and the Courses Sillabus were collected. The analysis has realized considering the dialectical pairs subject-object, content-form and theorypractise and has exposed that the discipline Didactic of Mathematics takes on the theoretical approach, that the adopted practical might be recognized by the movement to create, to plan, to execute, to manage and to evaluate didactic situations related to mathematics teaching, among others. Relating to curriculum -material, it has identified the approach of parts from knowledge that the didactic of mathematics as science may offered. To develop them, uses, in general way, lecture classes. Some of those courses intend to offer the formation for researchers in mathematics education. This document revealed the necessity to encourage discussions about the importance of that discipline for the initial formation for teachers.
\end{abstract}

Words-key: Didactic of Mathematics; Didactic of Mathematics in the Distance Learning Degree; Documental Analysis.

\section{La Asignatura Didáctica de la Matemática en los Cursos de Graduación en Matemática a Distancia: lo que presentan los documentos de estos cursos}

\begin{abstract}
Resumen
El estudio aquí presentado objetivó identificar más aspectos teóricos, prácticos, contenidos y formación considerados en la asignatura Didáctica de la Matemática en los cursos de Graduación en Matemática a Distancia. Para lograrlo, fue realizada una pesquisa documental a partir de los datos obtenidos en el sitio del Ministerio de la Educación. Fue identificado la existencia de 44 cursos en esta modalidad de enseñanza, posibilitando la coleta de 19 Planes Pedagógicos de Curso y 26 Matrices Curriculares. La análisis de las Matrices permitió identificar la asignatura Didáctica de la Matemática en 08 de estos cursos y fueron colectadas las Emendas de la asignatura. La análisis se realizó considerando los pares dialécticos teoríapráctica y contenido-forma y reveló que la asignatura Didáctica de Matemática asume enfoque teórico, que la práctica adoptada puede ser reconocida por el movimiento en el sentido de crear, planear, realizar, administrar y evaluar situaciones didácticas para la enseñanza de la matemática, entre otras. En relación a los contenidos programáticos, fue identificado el abordaje de parte de los conocimientos que la didáctica de la matemática como ciencia puede posibilitar. Para el desarrollo, fue adoptado, de modo general, forma expositiva en las clases. Algunos de estos cursos tienen la pretensión en la formación de investigadores en educación matemática. El estudio reveló la necesidad de fomentar discusiones sobre la importancia de la asignatura de la asignatura para la formación inicial de profesores.
\end{abstract}

Palabras clave: Didáctica de la Matemática; Graduación en Matemática a Distancia; Análisis Documental. 


\section{Introdução}

O número de cursos de Licenciatura em Matemática a Distância no Brasil elevou-se nas últimas décadas (SILVA, 2017). O fato pode associar-se, dentre outros motivos, ao interesse em democratizar o acesso ao conhecimento, oportunizando formação a todos aqueles que não têm condições de se deslocar aos grandes centros para cursar uma universidade. No entanto, suscita indagações, principalmente sobre o modo como se organiza o ensino dos componentes curriculares.

$\mathrm{Na}$ impossibilidade de um estudo sobre os modos de organização de todos os componentes curriculares destes cursos, delimitou-se o olhar para a disciplina Didática da Matemática almejando extrair algumas informações.

Inicialmente, esclarece-se o uso dos termos "componente curricular" e "disciplina", justificando a opção pelo segundo para referir-se à Didática da Matemática neste texto. Segundo o Artigo 14, inciso VIII da Resolução $\mathrm{n}^{\circ}$ 2, de 30 de janeiro 2012, que define Diretrizes Curriculares Nacionais para o Ensino Médio,

Os componentes curriculares que integram as áreas de conhecimento podem ser tratados ou como disciplinas, sempre de forma integrada, ou como unidades de estudos, módulos, atividades, práticas e projetos contextualizados e interdisciplinares ou diversamente articuladores de saberes, desenvolvimento transversal de temas ou outras formas de organização (BRASIL, 2012, p. 6).

Estabeleceu-se como objetivo, identificar quais aspectos teóricos, práticos, conteúdos e forma são considerados na disciplina Didática da Matemática nos cursos de Licenciatura em Matemática a Distância e optou-se pela pesquisa documental. Necessitava-se ter livre acesso às informações de forma on-line e, assim, focou-se nos cursos das instituições públicas brasileiras.

A análise documental possibilita identificar a presença ou não da disciplina Didática da Matemática no currículo da formação inicial docente a distância, bem como, o que se propõe para ela. Assim, o que se encontra elencado nos documentos destes cursos não reflete o pensamento e a opinião das autoras, sendo apenas a sua constatação.

O foco da análise é a disciplina de Didática da Matemática e, utilizam-se as expressões "didática" e "didática da matemática" ora com letras maiúsculas ora minúsculas, no decorrer do texto. Referindo-se às disciplinas Didática e Didática da Matemática, adotam-se iniciais maiúsculas e aos conhecimentos em didática e em didática da matemática, utilizam-se as iniciais minúsculas. 
Diferencia-se também as disciplinas Didática e Didática da Matemática para não considerar erroneamente que uma pode substituir a outra.

A disciplina Didática tem importância fundamental na formação docente, pois o futuro professor “[ ...] necessita de uma instrumentalização ao mesmo tempo teórica e técnica para que realize satisfatoriamente o trabalho docente, em condições de criar sua própria didática, ou seja, sua prática de ensino em situações didáticas específicas” (LIBÂNEO, 2013, p. 10). Mas, muitas vezes, ela é entendida como "A ciência e a arte de ensinar" (COSTA, 2013) e precisa ser discutida para que sua incorporação aos currículos da licenciatura não a reduza a discutir modelos de aulas.

Em outras situações é confundida com a Metodologia de Ensino que, segundo Costa (2013, p. 184) é “[...] o conjunto de métodos e técnicas que são utilizados a fim de que o processo ensino-aprendizagem se realize com êxito". Sugere Libâneo (2013), de que a Didática necessita ser vista

[...] como uma matéria de integração [que se nutre] dos conhecimentos e práticas desenvolvidos nas metodologias específicas e nas outras ciências pedagógicas para formular generalizações em torno dos conhecimentos e tarefas docentes comuns e fundamentais ao processo de ensino (LIBÂNEO, 2013, p. 9).

Deste modo, a Didática se conecta às metodologias, às práticas de ensino e ao estágio, pois “[...] todas as matérias do currículo partem, incluem e levam à prática de ensino [e] em particular, há uma fecundação mútua entre Didática e as metodologias específicas, não se concebendo uma sem as outras" (LIBÂNEO, 2013, p. 12).

Concorda-se com Libâneo (2011b, p. 5) que "A didática é uma disciplina que estuda o processo de ensino no qual os objetivos, os conteúdos, os métodos e as formas de organização da aula se combinam entre si, de modo a criar as condições e os modos de garantir aos alunos uma aprendizagem significativa."

Mas, se o foco é o processo de ensino de Matemática, há que se considerar “[...] que existe um saber matemático pedagógico que permite que a Matemática seja compreendida e apropriada por todos" (ESPINOSA, 2011, p. 56). Este saber direciona a pensar nos conhecimentos em didática da matemática que a disciplina Didática da Matemática pode oferecer, possibilitando “[...] que o professor de Matemática veja seu papel em um contexto mais amplo, assim como 'educador matemático'. Ser um educador matemático é muito mais do que um simples 'transmissor de conteúdo' [...]” (ESPINOSA, 2011, p. 9). 
Compactua-se com D’Amore (2007, p. 29) que a Didática da Matemática “[...] é uma disciplina autônoma, nem Didática geral nem Matemática, muito menos um receituário banal de bom senso" e apresenta como uma de suas principais tarefas,

[...] preparar profissionalmente o futuro professor, fornecendo-lhe as chaves de leitura para interpretar aquilo que acontece na sala de aula quando os 'polos' da tríade 'professor-aluno-conhecimento' interagem entre si em formas tão complexas que nenhuma competência puramente matemática (nem, é evidente, puramente pedagógica), e ainda menos a experiência e o bom sendo, podem explicar (D’AMORE, 2009, p. 12).

Se a Didática da Matemática "é a disciplina científica e o campo de pesquisa cujo objetivo é o de identificar, caracterizar e compreender os fenômenos e os processos que condicionam o ensino e a aprendizagem da Matemática” (D’AMORE, 2007, p. 97), ela possibilita conhecimentos ao professor para que este formule compreensões e reconheça que aspectos como o saber matemático, a transposição didática, os obstáculos epistemológicos, a formação de conceitos, dentre outros, são importantes na organização do ensino de Matemática.

Na visão de D’Amore (2007), ela é um dos subsistemas que compõem a área Educação Matemática que, por sua vez, é compreendida como todo um sistema social complexo e não homogêneo, abarcando teoria, prática e desenvolvimento concernente ao ensino e à aprendizagem da Matemática.

Porém, não é foco discutir tais questões, mesmo sendo de extrema importância. O intuito é o estudo e a análise dos documentos dos cursos de Licenciatura em Matemática a Distância almejando identificar aspectos teóricos, práticos, conteúdos e forma adotados na disciplina e reconhecidos através dos pares dialéticos. Identificação que pode contribuir com discussões relacionadas à formação inicial docente, a qual é o momento formal onde os processos de aprender a ser professor e aprender a ensinar começam a se constituir.

\section{O caminho metodológico da investigação}

Objetivando identificar quais aspectos teóricos, práticos, conteúdos e forma são considerados na disciplina Didática da Matemática nos cursos de Licenciatura em Matemática a Distância (LMD), optou-se pela pesquisa documental. A opção justifica-se por este modo de investigação ser realizado "[...] preferencialmente sobre documentação escrita [que] apresentam-se estáveis no tempo e ricos como fonte de informação [...]” (FIORENTINI, LORENZATO, 2009, p. 102-103), revelando os indícios que se objetiva.

Para se chegar aos documentos, mapeou-se o universo em investigação no primeiro semestre de 2017, realizando pesquisa no sítio do Ministério da Educação (MEC) no link 
http://emec.mec.gov.br. Buscou-se identificar os cursos de Licenciatura em Matemática a Distância oferecidos por instituições públicas brasileiras (IES) e encontraram-se 43 instituições credenciadas e com autorização. Percebeu-se que uma delas oferecia também o curso de Licenciatura em Ciências Naturais e Matemática a Distância. Assim, identificaram-se 44 cursos oferecidos no país e expandidos através dos polos de apoio em quase todos os estados brasileiros, não aparecendo registros deles no Amazonas (AM), Espírito Santo (ES), Rondônia (RO) e no Distrito Federal (DF). Estes dados estão apresentados na tabela a seguir:

Tabela 1- IES com oferta de curso de Licenciatura em Matemática a Distância.

\begin{tabular}{|c|c|c|c|}
\hline Instituição - Estado & Sigla & $\begin{array}{c}\mathbf{N}^{\mathbf{0}} \\
\text { Polos }\end{array}$ & Localização Polos \\
\hline Universidade Federal de Pelotas - RS & UFPEL & 29 & $1(\mathrm{SC}), 1(\mathrm{PR})$ e $27(\mathrm{RS})$ \\
\hline Universidade Federal do Rio Grande do Sul - RS & UFRGS & 15 & $1(\mathrm{MS})$ e $14(\mathrm{RS})$ \\
\hline Universidade Federal do Rio Grande - RS & FURG & 5 & $5(\mathrm{RS})$ \\
\hline Universidade Federal de Santa Catarina - SC & UFSC & 28 & 11 (MA) e 17 (SC) \\
\hline Universidade Estadual de Ponta Grossa - PR & UEPG & 28 & 28 (PR) \\
\hline $\begin{array}{l}\text { Instituto Federal de Educação, Ciência e Tecnologia do } \\
\text { Triângulo Mineiro - MG }\end{array}$ & IFTM & 8 & $4(\mathrm{MG})$ e $4(\mathrm{SP})$ \\
\hline Universidade Federal de Ouro Preto - MG & UFOP & 17 & $13(\mathrm{MG})$ e $4(\mathrm{SP})$ \\
\hline Universidade Federal de São João Del Rei - MG & UFSJ & 12 & $5(\mathrm{MG})$ e $7(\mathrm{SP})$ \\
\hline Universidade Federal do Estado do Rio de Janeiro - RJ & UNIRIO & 5 & $5(\mathrm{RJ})$ \\
\hline Universidade Federal Fluminense - RJ & UFF & 18 & $18(\mathrm{RJ})$ \\
\hline $\begin{array}{l}\text { Instituto Federal de Educação, Ciência e Tecnologia do } \\
\text { Norte de Minas Gerais - MG }\end{array}$ & IFNMG & 2 & 2 (MG) \\
\hline Universidade Federal de Juiz de Fora - MG & UFJF & 12 & $12(\mathrm{MG})$ \\
\hline Universidade Federal de Minas Gerais - MG & UFMG & 8 & $8(\mathrm{MG})$ \\
\hline Universidade Federal de Viçosa - MG & UFV & 4 & $4(\mathrm{MG})$ \\
\hline $\begin{array}{l}\text { Universidade Federal dos Vales do Jequitinhonha e Mucuri } \\
\text { - MG }\end{array}$ & UFVJM & 7 & 7 (MG) \\
\hline $\begin{array}{l}\text { Fundação Universidade Federal de Mato Grosso do Sul - } \\
\text { MS }\end{array}$ & UFMS & 8 & 8 (MS) \\
\hline Fundação Universidade Federal do Mato Grosso - MT & UFMT & 6 & 6 (MT) \\
\hline Fundação Universidade Federal do Mato Grosso - MT $(*)$ & UFMT & 12 & $12(\mathrm{MT})$ \\
\hline Universidade Federal de Goiás - GO & UFG & 5 & $5(\mathrm{GO})$ \\
\hline Fundação Universidade Federal do Tocantins - TO & UFT & 14 & 14 (TO) \\
\hline Universidade do Tocantins - TO & UNITINS & 8 & $8(\mathrm{TO})$ \\
\hline Universidade Federal do Acre - AC & UFAC & 9 & $9(\mathrm{AC})$ \\
\hline $\begin{array}{l}\text { Instituto Federal de Educação, Ciência e Tecnologia do Pará } \\
\text { - PA }\end{array}$ & IFPA & 9 & 1 (PA) e 8 (RR) \\
\hline Universidade Federal do Pará - PA & UFPA & 10 & $1(\mathrm{AP})$ e 9 (PA) \\
\hline Universidade do Estado do Pará - PA & UEPA & 1 & $1(\mathrm{PA})$ \\
\hline Universidade Federal de Roraima - RR & UFRR & 9 & 9 (RR) \\
\hline Universidade Federal do Amapá - AP & UNIFAP & 5 & $5(\mathrm{AP})$ \\
\hline Universidade Federal do Maranhão - MA & UFMA & 9 & 9 (MA) \\
\hline Universidade Estadual do Piauí - PI & UESPI & 8 & $8(\mathrm{PI})$ \\
\hline Universidade Federal do Piauí - PI & UFPI & 28 & $1(\mathrm{BA})$ e $27(\mathrm{PI})$ \\
\hline $\begin{array}{l}\text { Instituto Federal de Educação, Ciência e Tecnologia do } \\
\text { Ceará - CE }\end{array}$ & IFCE & 13 & 13 (CE) \\
\hline
\end{tabular}




\begin{tabular}{|l|l|c|l|}
\hline Universidade Estadual do Ceará - CE & UECE & 6 & $6(\mathrm{CE})$ \\
\hline Universidade Federal do Ceará - CE & UFC & 12 & $12(\mathrm{CE})$ \\
\hline $\begin{array}{l}\text { Instituto Federal de Educação, Ciência e Tecnologia de } \\
\text { Pernambuco - PE }\end{array}$ & IFPE & 8 & 1 (AL), 1 (BA) e 6 (PE) \\
\hline Universidade Federal de Pernambuco - PE & UFPE & 6 & 6 (PE) \\
\hline Universidade do Estado da Bahia - BA & UNEB & 41 & $41(\mathrm{BA})$ \\
\hline Universidade Estadual do Sudoeste da Bahia - BA & UESB & 5 & $5(\mathrm{BA})$ \\
\hline Universidade Federal da Bahia - BA & UFBA & 18 & $18(\mathrm{BA})$ \\
\hline Universidade Federal do Recôncavo da Bahia - BA & UFRB & 1 & 1 (BA) \\
\hline Universidade Federal da Paraíba - PB & UFPB & 21 & 2 (BA) e 19 (PB) \\
\hline Universidade Federal do Rio Grande do Norte - RN & UFRN & 10 & $10(\mathrm{RN})$ \\
\hline Universidade Federal Rural do Semi-Árido - RN & UFERSA & 4 & 4 (RN) \\
\hline Universidade Federal de Alagoas - AL & UFAL & 3 & $3(\mathrm{AL})$ \\
\hline Universidade Federal de Sergipe - SE & UFS & 14 & $14(\mathrm{SE})$ \\
\hline
\end{tabular}

* Curso de Licenciatura em Ciências Naturais e Matemática a Distância.

Fonte: Dados da Pesquisa, MEC - http://emec.mec.gov.br. Acesso: Abril de 2017. Organizado pelas autoras.

Após, buscou-se na página do curso os documentos - Planos Pedagógicos de Curso (PPC), Matrizes Curriculares (MC) e Ementas do Curso e da disciplina Didática da Matemática (EmDM). Em 18 destas IES não foi possível acesso aos documentos on-line. Exigia-se o cadastro como estudante ou a plataforma estava desatualizada. Então o contato se deu via email para que, na medida do interesse da IES, fossem disponibilizados os documentos. Duas delas retornaram o contato, as outras não responderam a solicitação.

Assim, coletou-se 19 PPCs e 26 MCs e foi possível identificar a presença ou não da disciplina Didática da Matemática no currículo da licenciatura, bem como, o período em que ela era oferecida, sua carga horária e a denominação atribuída à ela. Na análise das 26 Matrizes Curriculares, percebeu-se que em 22 destes cursos havia a presença das disciplinas Didática Geral e/ou Didática da Matemática. Quatro (04) cursos não apresentavam nenhuma delas. Dentre os 22 cursos, 14 contemplavam apenas a disciplina Didática Geral, 04 cursos apenas a disciplina Didática da Matemática e 04 apresentavam as duas. Portanto, sendo o foco a disciplina Didática da Matemática e aparecendo em 08 dos cursos, a análise restringiu-se a eles. Todavia, pressupõem-se que nos demais cursos os conhecimentos em didática da matemática sejam abordados na disciplina Didática Geral ou em outras disciplinas do currículo.

A análise documental dos 08 cursos, mais especificamente, das Ementas da disciplina Didática da Matemática extraídas dos PPCs, foi realizada buscando reconhecer o movimento dos pares dialéticos teoria-prática e conteúdo-forma, no intuito de atender ao objetivo proposto. Porém, não se ignoram aspectos importantes da didática da matemática como campo de conhecimento e pesquisa.

Ao assumir os pares dialéticos, assume-se que a relação teoria-prática se constitui pela “[...] dialética da inter-relação entre o pensamento e o ser, [pela] compreensão do lugar da 
prática na teoria do conhecimento [...]" (KOPNIN, 1978, p. 50). E uma análise documental identificando quais aspectos teóricos são considerados na disciplina e qual prática se adota para o desenvolvimento deles pode suscitar discussões relevantes sobre o modo de organização do seu ensino.

Assim como entendendo que a relação do conteúdo com a forma adotada na disciplina “[...] estão intrinsicamente ligados ao movimento de apropriação de pensamento do indivíduo, posto que conteúdos determinam formas, que por sua vez atribuem mudanças em conteúdos já estruturados no pensamento, assim, gerando nova forma ao conhecimento e um novo pensamento" (CHEPTULIN, 1982 apud VIDIGAL, DIAS, FRANCO, 2017, p. 613), os conteúdos elencados na Ementa da disciplina dos cursos refletem determinadas formas de organização e desenvolvimento do seu ensino.

Destaca-se que, ao analisar estas Ementas, algumas apresentam poucas informações. Então, buscou-se identificar no PPC elementos que revelassem os aspectos elencados para esta discussão, considerando-se que a proposta definida pela IES para o curso reflete-se nas disciplinas, mesmo quando implícita na Ementa.

Outro destaque é que, para preservar a identidade das IES analisadas, adotou-se, aleatoriamente, letras do alfabeto, diferenciando-as. Não se pretende atribuir juízo de valor e sim identificar os aspectos teóricos, práticos, conteúdos e forma de desenvolvimento destes são considerados na disciplina de Didática da Matemática dos cursos de Licenciatura em Matemática a Distância.

\section{Aspectos teóricos e práticos identificados nos documentos}

Ao olhar os documentos almejava-se identificar quais aspectos teóricos e práticos são considerados na disciplina Didática da Matemática nos cursos de Licenciatura em Matemática a Distância. Considera-se que a relação teoria-prática se dá na compreensão de que "[...] a primeira depende da segunda na medida em que a prática é fundamento da teoria, já que determina o horizonte de desenvolvimento e progresso do conhecimento" (VÁZQUEZ, 2007, p. 243). Sendo um movimento indissociável e dialético, possibilita que a teoria complemente a prática e vice-versa. Ou seja, a prática encontra suporte na teoria e, quando se retorna à prática, esta é assumida sob outro olhar.

Se a disciplina Didática da Matemática tem como uma de suas principais tarefas preparar profissionalmente o futuro professor, os aspectos práticos adotados em relação aos aspectos teóricos e elencados na Ementa, revelam indícios quanto à intenção da formação inicial. Concorda-se com Gamboa (2010) quando afirma que 
[...] a relação teoria-prática é, em verdade, uma relação dialética [e], como tal, não procura o equilíbrio, o ajuste, a acomodação de uma a outra, visa a sua contradição, isto é, a tensão permanente entre elas. [A] teoria transforma-se no contrário da prática e vice-versa. Se não é assim, deixariam de se constituir numa relação dialética (GAMBOA, 2010, p. 1).

Quando se considera o conhecimento teórico em didática da matemática, entende-se que este ilumina o professor em suas reflexões sobre sua ação em sala de aula. Ação que não pode constituir-se por uma prática vazia, desvinculada do conhecimento teórico ou baseada apenas no conhecimento empírico, pois “[...] a aplicação prática do conhecimento empírico é restrita, sendo, no sentido científico, um ponto de partida qualquer para a construção da teoria" (KOPNIN, 1978, p. 152).

Assim, buscou-se nas Ementas da disciplina, quais aspectos teóricos são considerados nos cursos e estes se apresentam na tabela abaixo:

Tabela 2 - Aspectos teóricos identificados na Ementas da disciplina Didática da Matemática dos cursos analisados.

\begin{tabular}{|c|c|}
\hline Instituição & Aspectos teóricos \\
\hline A & $\begin{array}{l}\text { "Noções das Teorias da Educação Matemática [Teoria da Situações, dos Campos Conceituais, } \\
\text { Antropológica do didático], elementos teóricos e metodológicos [...]" }\end{array}$ \\
\hline $\mathrm{C}$ & "[...] princípios didáticos [...] sistema de avaliação da aprendizagem." \\
\hline D & $\begin{array}{l}\text { "[...] concepções referentes à educação e à formação do educador matemático, }[\ldots] \text { diferentes } \\
\text { abordagens do ensino da matemática, }[\ldots] \text { concepção educacional de ensino da matemática, }[\ldots] \\
\text { recursos didáticos no ensino da Matemática, [...] organização do processo de ensino e } \\
\text { aprendizagem matemática." }\end{array}$ \\
\hline G & "[...] metodologia de ensino, $[\ldots]$ planejamento, análise de livros didáticos e paradidáticos [...]" \\
\hline $\mathrm{N}$ & $\begin{array}{l}\text { "[...] sistema didático, [...], Relação 'dialética ferramenta-objeto' de Douady, 'Obstáculos } \\
\text { Epistemológicos' de Brousseau e a metodologia da 'Engenharia didática'” de Artigue." }\end{array}$ \\
\hline Q & "[...] relação teoria-prática na construção da matemática e no trabalho pedagógico do professor." \\
\hline $\mathrm{R}$ & "[...] métodos de ensino da matemática, $[\ldots]$ sequências didáticas $[\ldots] "$ \\
\hline $\mathrm{S}$ & "[...] introdução à Didática da Matemática; [...] fenômenos didáticos [...]" \\
\hline
\end{tabular}

FONTE: Ementa da disciplina Didática da Matemática dos cursos de Licenciatura em Matemática a Distância. Acesso em: Junho de 2017. Organizado pelas autoras.

Identificados, percebe-se que estes aspectos teóricos fornecem condições de o professor refletir sobre sua atuação em sala de aula. Eles vinculam-se ao ensino da Matemática, possibilitando conhecimentos para uma futura intervenção na realidade. De modo geral, eles contemplam questões importantes da didática da matemática como campo de conhecimento, porém, cada curso define aqueles que julga mais importantes.

Buscam-se, então, quais aspectos práticos se adotam na hora de abordá-los, assumindo como norte que "[...] a prática define os objetivos do pensamento e este, por sua vez, desempenha papel essencial na determinação dos fins da atividade prática [legitimando-a] como critério ativo do pensamento [...]" (KOPNIN, 1978, p. 170). Esta prática coloca exigência à 
teoria quando "[...] contribui para ampliar tanto o horizonte dos problemas como o das soluções" (VÁZQUEZ, 2007, p. 243). Neste sentido, se reconhece que a teoria ilumina as questões que a prática faz emergir, possibilitando o encontro de respostas e a proposta de prática assumida na disciplina Didática da Matemática diante dos aspectos teóricos considerados, revela indícios da organização do ensino com vistas à formação do professor de Matemática.

Voltando-se aos documentos, identifica-se que na IES A, a disciplina intenciona intervir na realidade propondo formação para professor pesquisador. Assenta sua prática na realização de análises e discussões de artigos e dissertações em Educação Matemática e no planejamento de projetos de pesquisa para apresentação aos colegas em aulas por videoconferência (EmDM IES A). Pretensão identificada quando possibilita ao licenciando conhecimentos para o enfrentamento e desenvolvimento de situações interdisciplinares na perspectiva das Diretrizes Curriculares Nacionais para o Ensino Médio (DNCEM, 2012), dos Parâmetros Curriculares Nacionais (PCN, 1997) e da Proposta Curricular do estado onde o curso se insere (PPC IES A). Também intenciona que os licenciandos apliquem projetos temáticos no campo do estágio (EmDM IES A). Mas, na Matriz Curricular do curso, a disciplina ocorre após os estágios supervisionados, no último período do curso e, assim, os conhecimentos teóricos definidos como noções das Teorias em Educação Matemática são proporcionados ao licenciando posteriormente à realização dos estágios, contribuindo nas possíveis discussões do que foi vivenciado.

A IES N, por sua vez, propõe colocar em prática as teorias estudadas por meio de planejamento, execução e avaliação de situações didáticas interdisciplinares, buscando a organização e intervenção nas situações educativas e a formulação de propostas de intervenção pedagógica. Apresenta intenções de "Criar, planejar, realizar, gerir e avaliar situações didáticas eficazes para a aprendizagem e para o desenvolvimento dos alunos, utilizando o conhecimento da área de matemática, das temáticas sociais transversais ao currículo escolar, dos contextos sociais [...]" (EmDM IES N). Os aspectos teóricos apontados se revelam inseridos nos momentos da prática adotada na disciplina, sendo considerados na organização de propostas de situações didáticas pelo licenciando.

A IES D aponta interesse em proporcionar ao licenciando a retomada do movimento histórico da profissão docente, a apresentação de diferentes concepções de conhecimento, educação e didática e as diferentes perspectivas de análise sobre a escola, o ensino e a aprendizagem, como fundamento para a “[...] produção de um projeto de ensino de matemática para um dos tópicos estudados na disciplina” (EmDM IES D). Pontua-se que os aspectos 
teóricos poderiam ser mais específicos ao ensino da Matemática, trazendo mais contribuições às produções dos licenciandos.

Na IES C, identifica-se “[...] referência a princípios didáticos [porém não identificados], formas de organizar o ensino, avaliação da aprendizagem matemática e intenções do professor no processo de ensino" (EmDM IES C). Percebe-se que os aspectos práticos adotados não revelam quais princípios didáticos consideram e que as questões que envolvem planejamento de ensino não estão claramente expostas na Ementa. Sugere-se apenas que a " [...] construção de uma prática pedagógica de Matemática [..] se desenvolva dentro dos princípios didáticos [utilizando-se de] planejamento de ensino" (EmDM IES C). No entanto, não explicita sua pretensão com a construção de uma prática pedagógica de Matemática, ou seja, se ela será desenvolvida e seus resultados analisados e discutidos na disciplina.

Em outra IES, identificada por G, percebe-se aspectos práticos ao sugerir abordar "Metodologias e estratégias de ensino da matemática, fundamentos da didática aplicados ao conhecimento matemático (PPC IES G) e conhecimentos para a construção de "[...] sequências didáticas [...]" (EmDM IES G) onde se articulam os conhecimentos específicos aos didáticopedagógicos. Para isso, propõe "[Selecionar e organizar] conteúdos para uma boa aula, [possibilitando compreensões para o] desenvolvimento de estratégias de ensino da matemática [e] planejamento de sequências didáticas [para aplicação de] atividades no Laboratório de ensino de Matemática" (EmDM IES G). Entende-se que os aspectos teóricos propostos são considerados na organização de sequências didáticas a serem desenvolvidas no laboratório de ensino e que os resultados alcançados serão discutidos. Neste sentido, a prática adotada contemplaria os aspectos teóricos considerados, sendo estes o ponto de partida que iluminaria a prática, retornando à teoria e, assim, contribuindo com a formação docente.

Na IES Q, aponta-se indícios da prática ao estabelecer “[...] relação teoria-prática na construção da matemática e no trabalho pedagógico do professor [...]” (EmDM IES Q) como forma de propiciar ao licenciando condições de organizar o ensino da matemática. No entanto, não fica explícito de que modo esta relação acontece e que prática, ou seja, de que modo esta relação se efetiva. Os aspectos teóricos e práticos não estão claramente definidos na Ementa da disciplina.

A IES R expõe intenções de que os conhecimentos sobre métodos e estratégias de ensino da matemática possibilitem que o licenciando reflita e questione sua própria prática. Propõe como prática, desenvolver o espírito investigativo através de “[...] reflexões sobre o que é matemática, [o] que se ensina e o que se aprende, [sendo capacitados a desenvolverem] projetos interdisciplinares, colocando em prática os planejamentos de unidades didáticas [através da] 
implementação por meio de aulas simuladas das aulas preparadas [abrangendo diversos] campos do conhecimento matemático" (EmDM IES R). Busca estabelecer a relação teoriaprática, fornecendo conhecimentos teóricos ao licenciando para o desenvolvimento dos planejamentos produzidos na disciplina e a prática adotada, quando sugere reflexões sobre os resultados alcançados, assume como norte os aspectos teóricos considerados.

$\mathrm{Na}$ IES S, identifica-se interesse em oportunizar conhecimentos para que os licenciandos tenham condições de "[produzir] materiais didáticos [e planejar e executar] projetos coletivos na escola de educação básica" (PPC IES S). A Ementa da disciplina não expõe claramente os aspectos práticos adotados em relação aos teóricos. Uma possibilidade de prática pode ser pelo estudo isolado do licenciando, ou então pela apresentação feita pelo professor, sem debates e discussões. Nesta IES, buscou-se informações complementares no PPC para clarificar a prática adotada na disciplina.

Diante da identificação dos aspectos teóricos e considerando o que pode ser caracterizado como prática na disciplina Didática da Matemática dos cursos de Licenciatura em Matemática a Distância, outras dúvidas emergem. Quais conteúdos programáticos estão elencados na Ementa e qual a forma adotada pela disciplina para o seu desenvolvimento? Considera-se que este reconhecimento também fornece indícios para a compreensão sobre o modo de organização do ensino proposto na disciplina, sendo apresentados na sequência.

\section{Conteúdo e forma identificados nos documentos}

Se a forma é a configuração visível do conteúdo, a parte do fenômeno que assume a função de motivar o sentido da mente para determinado conceito, esta pode ser compreendida como a aparência física do conteúdo. Neste sentido, a indissociabilidade do conteúdo e da forma revelam-se pela

[...] correlação orgânica e interdependente [entre eles], de maneira que um fator não pode existir sem o outro. $\mathrm{O}$ conteúdo deve ser visto como um todo unitário, no qual os elementos que compõem um determinado objeto estruturam uma totalidade dialética em movimento. O conteúdo vem a ser o conjunto de elementos (aspectos, traços, sinais, processos) que compõem o objeto, as suas funções próprias e as ações que realiza. A forma é a maneira pela qual os componentes do objeto, que definem o conteúdo, se congregam, compondo a forma do conteúdo (MIORIN, 1990, p. 47).

Deste modo, “[...] ao variar o conteúdo, a forma varia imediatamente [e a] forma pode se manter freada por qualquer fator que atue em sentido contrário à influência do conteúdo sobre ela" (MIORIN, 1990, p. 47), o que justifica analisar o conteúdo programático elencado nas Ementas da disciplina dos 08 cursos em questão, bem como, a forma adotada para o seu desenvolvimento. 
Esta análise revela que, em um deles, o conteúdo programático proposto tem o foco na formação à pesquisa, quando oferece “[...] elementos para o exercício de ser professor pesquisador [garantindo] o desenvolvimento de atitudes reflexivas e investigativas, [...] (PPC IES A). Apresenta conteúdos que contemplam a abordagem de

\begin{abstract}
Noções das teorias da Educação Matemática [Situações: Brousseau, Campos Conceiturais: Vergneau (sic) ${ }^{3}$, Antropológica do Didático: Chevallard], tendências metodológicas [modelagem, problemas, história da Matemática] e Identificação do Problema da pesquisa, [...] do referencial teórico; [...] da metodologia; [...] dos resultados (EmDM IES A).
\end{abstract}

Outro curso da IES R também propõe formação de professor pesquisador sugerindo "[...] qualificar seus graduados para a pesquisa em Educação Matemática [...]” (PPC IES R). Neste sentido e, também, pensando na formação para a docência, busca promover "Reflexões sobre o que é Matemática, [seus] objetivos de ensino [conduzindo a] apresentações de diversos métodos (resolução de problemas, [...] História da Matemática, uso de materiais didáticos [e] tecnológicos, modelagem [...]" (EmDM IES R).

Os demais cursos não fazem referência quanto a formação para ser pesquisador, entendendo-se, assim, que o foco é a formação para a docência. O desenvolvimento dos conteúdos propostos, apresentados na tabela seguinte, considera o aluno, o professor, o conhecimento (conteúdo matemático) e os métodos e as possíveis estratégias de ensino. Ao considerar estes elementos, os conteúdos oportunizam ao licenciando a aquisição de conhecimentos que estabelecem relação entre o ensino e a aprendizagem, bem como, conhecimentos de métodos e estratégias de ensino relacionadas aos conteúdos matemáticos. Porém, não se pode afirmar que a forma adotada na disciplina para o seu desenvolvimento considere os possíveis contextos onde ocorrerão o ensino e a aprendizagem da Matemática dos futuros licenciandos.

\footnotetext{
${ }^{3} \mathrm{O}$ nome de Gérard Vergnaud aparece escrito de modo incorreto na Ementa da disciplina Didática da Matemática da IES. Optou-se por manter no texto o modo encontrado, corrigindo-o em nota de rodapé.
} 
Tabela 3 - Conteúdos elencados na Ementa da disciplina Didática da Matemática dos cursos analisados.

\begin{tabular}{|c|l|}
\hline Instituição & \multicolumn{1}{c|}{ Conteúdo } \\
\hline $\mathrm{C}$ & "[...] objetivos, conteúdos, formas organizativas do ensino, métodos, meios de ensino [...]" \\
\hline $\mathrm{D}$ & $\begin{array}{l}\text { "Fundamentos e métodos da didática da Matemática; Estudo do processo educativo escolar [...]; A } \\
\text { didática como prática fundamentada na ação do educador matemático; [...] transposição didática; } \\
\text { Planejamento [...]; Recursos didáticos [...]" }\end{array}$ \\
\hline $\mathrm{G}$ & $\begin{array}{l}\text { "Metodologias necessárias para a apresentação de uma boa aula. [...] Estratégia para o ensino da } \\
\text { Matemática: [...] situações problemas - jogos. [...] sequências didáticas." }\end{array}$ \\
\hline $\mathrm{N}$ & $\begin{array}{l}\text { "Estrutura e funcionamento do sistema didático como modelo teórico, Obstáculos epistemológicos; } \\
\text { Dialética Ferramenta-Objeto; Engenharia didática; Campos Conceituais; [...]" }\end{array}$ \\
\hline $\mathrm{S}$ & $\begin{array}{l}\text { "Introdução à Didática da Matemática; o sistema didático; a sala de aula de matemática e os } \\
\text { diferentes fenômenos didáticos; transposição didática (externa e interna); teoria das situações } \\
\text { didáticas; teoria dos campos conceituais; erros e obstáculos." }\end{array}$ \\
\hline $\mathrm{Q}$ & "Compromisso político do educador no ensino da matemática. [...] lúdico na matemática." \\
\hline
\end{tabular}

FONTE: Ementa da disciplina Didática da Matemática dos cursos de Licenciatura em Matemática a Distância.

Acesso em: Junho de 2017. Organizado pelas autoras.

Em relação à forma adotada pela disciplina para o desenvolvimento dos conteúdos programáticos na IES C, encontram-se propostas no sentido de criar

[...] atividades de caráter científico, cultural e acadêmico articulando-se e enriquecendo o processo formativo do professor como um todo. Seminários, apresentações, exposições, participação em eventos científicos, estudos de caso, visitas, ações de caráter científico, técnico, cultural e comunitário, produções coletivas, monitorias, resolução de situações-problema, projetos de ensino, ensino dirigido, aprendizado de novas tecnologias de comunicação e ensino, relatórios de pesquisas [...] (PPC IES C).

Propõe a "Construção de uma prática pedagógica de Matemática [para o Ensino Básico], na direção de um processo de ensino/aprendizagem [...] coerente e criativo [que] se integrem [...] com a intencionalidade educativa do professor de Matemática, da escola e da sociedade" (EmDM IES C).

Na IES D, a Ementa da disciplina não explicita claramente a forma adotada. Buscou-se informações no PPC, o qual sugere concretizar-se "[...] através de uma efetiva articulação entre o conteúdo específico de Matemática e o conteúdo pedagógico, entre a teoria e a prática na sala de aula, atendendo às exigências das transformações científicas e tecnológicas [...]" (PPC IES D), pois propõe o desenvolvimento de atividades presenciais e a distância, prevendo nas atividades presenciais "Palestras que abordem em forma de síntese os conteúdos das diferentes disciplinas [...]; Apresentação dos resultados das pesquisas temáticas ou por meio de comunicações orais ou de outra forma de participação; Avaliações escritas [...]" (PPC IES D). Quanto às atividades a distância, não faz referências, podendo-se pensar em momentos que o licenciando realiza seus estudos individuais e executa as atividades determinadas pelo professor. Considera-se também que, através de “[...] reflexões sobre diferentes abordagens do 
ensino da matemática; [que conduzam a] compreensões [sobre] o ensino e sua organização" (EmDM IES D), adota-se estudos prévios do licenciando e reflexões e discussões nos encontros presenciais.

Na IES G a disciplina denomina-se "Didática para o Ensino de Matemática", e se propõe como forma de desenvolvimento dos conteúdos

[...] o estudo e a análise crítica de atividades e experiências de ensino da Matemática [...] apresentação, seleção e organização de conteúdos de Matemática pertinentes a Educação Básica [que possibilitem o desenvolvimento do pensamento e para aplicação dos conceitos apreendidos em] atividades no Laboratório de Ensino da Matemática (EmDM IES G).

Na IES N, a Ementa também não deixa claro a forma adotada na disciplina. O PPC da IES revela intenções quanto ao estabelecimento da relação “[...] teoria e prática, numa perspectiva reflexiva e dialógica entre esses dois polos não antagônicos e sim complementares e interdependentes [para] mobilizar os conhecimentos, transformando-o em ação." (PPC IES N). Apenas sugere-se a “[...] construção do conhecimento matemático [...] (EmDM IES N) de “[...] modo abrangente e para além do domínio de conhecimentos e competências necessários ao exercício da docência no Ensino Fundamental e Médio" (PPC IES N), buscando uma “aproximação entre a formação prática e reflexão teórica [...]” (PPC IES N). A proposta de trabalho adotada sugere pensar na promoção de reflexões e diálogos constantes conduzindo a construção do conhecimento pelo licenciando.

A IES S propõe, em relação aos conteúdos programáticos, “Analisar criticamente [...] selecionando e produzindo material didático para o desenvolvimento de aulas atrativas e significativas para o seu alunado [...] que o auxilie na elaboração de suas estratégias de ensinoaprendizagem para a sua futura profissão.” (PPC IES S). A Ementa apresenta poucos indícios que contribuam com a identificação da forma adotada. Pressupõe-se que a proposta do curso estabelecida em seu PPC, estenda-se às disciplinas e que assim esteja organizada e desenvolvida a disciplina nesta IES. Deste modo, promover análises e produzir materiais para a ação docente do futuro licenciando pode se constituir na forma adotada pela disciplina nesta IES.

A IES Q apresenta como forma de desenvolvimento das disciplinas "[...] contextualização associada à interdisciplinaridade; [...] reflexão na forma como a matemática é ensinada, sem esquecer que foi construída pelo homem ao longo dos séculos e impulsionada pela sociedade para suprir as [suas] necessidades [...]" (PPC IES Q). A disciplina denomina-se por "Prática de Ensino V - Didática da Matemática" e sua ementa não revela explicitamente a forma adotada. Pode-se pensar em promoção de atividades que "[favoreçam] percursos de 
enriquecimento da experiência do ensinar-aprender nos espaços da educação [pelo estabelecimento de] relações entre os conhecimentos da Matemática e a realidade" (PPC IES Q) os quais possibilitem que o licenciando tenha condições de, no exercício da docência, contextualizar e aplicar o conhecimento. Ao denominar a disciplina como "Prática de Ensino Didática da Matemática”, entende-se que a IES assume Prática de Ensino e Didática da Matemática como sinônimos.

A análise dos documentos dos 08 cursos de Licenciatura em Matemática a Distância que apresentam a disciplina de Didática da Matemática no currículo da formação inicial apontou para outra possibilidade de revelar a dialética conteúdo-forma, ou seja, pela análise das bibliografias sugeridas na Ementa da disciplina. Considera-se que pelas obras e autores adotados seja possível identificar alguns indícios dos conteúdos propostos e de uma possível forma assumida na disciplina pelos professores que a ministram. Estas obras e autores estão apresentados na tabela seguinte. Optou-se pela relação de todas as obras consideradas na disciplina e seus autores (por ordem alfabética), em quais cursos aparecem e se é bibliografia básica ou complementar. A única Ementa da disciplina que não apresenta indicações de bibliografia é a da IES C, sendo este um dos motivos de considerar a superficialidade das Ementas.

Tabela 4- Bibliografias da disciplina Didática da Matemática relacionadas nas Ementas dos cursos analisados.

\begin{tabular}{|l|l|c|c|}
\hline AUTOR & OBRA & INSTITUIÇÃO & TIPO \\
\hline ALMOULOUD, S. A. & $\begin{array}{l}\text { Fundamentos da Didática da Matemática. UFPR, } \\
2007 .\end{array}$ & A e S & Básica \\
\hline BERLOQUIM, P. & 100 jogos numéricos. Lisboa: Ed. Gradiva, 1991. & Q & Básica \\
\hline BEZERRA, J. & $\begin{array}{l}\text { Vamos gostar da matemática. RJ: Philobiblion, } \\
1985 .\end{array}$ & Q & Complementar \\
\hline BICUDO, M. A. V. (org.) & Educação Matemática. São Paulo: Ed. Moraes, s/d. & Q & Complementar \\
\hline BICUDO, M. A. V. et all. & Educação Matemática, Ed. Moraes. 2005. & G & Complementar \\
\hline BOTH CARVALHO, N. T. & $\begin{array}{l}\text { Iniciação a Pesquisa em Didática da Matemática: } \\
\text { Livro Didático/EAD/UFSC, 2010. }\end{array}$ & A & Básica \\
\hline BRANDÃO, C. R. & O que é educação. São Paulo Brasiliense, 1991. & D & Básica \\
\hline
\end{tabular}

Continuação 


\section{BRASIL. Ministério da}

Educação (MEC). Secretaria de

Educação Média e Tecnológica

(Semtec).

BRASIL. Ministério da

Educação (MEC). Conselho

Nacional de Educação.

BRASIL. Ministério da

Educação e do Desporto.

Secretaria de Educação

Fundamental.

BRITO MENEZES, A.P.A.
Parâmetros Curriculares Nacionais para o Ensino

Médio. Brasília: MEC/Semtec, 1999

Diretrizes Curriculares Nacionais para a Formação de Professores da Educação Básica, em nível

superior, curso de licenciatura, de graduação plena. Resolução CNE/CP 1/2002.

Parâmetros curriculares nacionais terceiro e quarto ciclos do ensino fundamental: introdução aos parâmetros curriculares nacionais. Brasília, DF: MEC/SEF, 1998.

Contrato Didático e Transposição Didática: interrelações entre os fenômenos didáticos na introdução à álgebra elementar. Anais do Simpósio Internacional de Pesquisa em Educação Matemática - SIPEMAT - Recife: Editora da UFPE, 2006.

CANDAU, V. M. (Org.).

CARRAHER, T. N. et al.

CASTELNUOVO, E.

CHEVALLARD, Y.; BOSCH,

M.; GASCÓN, J.

COLL, C. et al.

COMÉNIUS, J. A.

CORDEIRO, $\mathrm{J}$

COURANT, R.; ROBBINS, $\mathrm{H}$.

D'AMBRÓSIO, U.

D'AMORE, B.

D'AMORE, B.

DANTE, L. R.

DANTE, L. R.

DELIZOICOV, D.

DUARTE, $\mathrm{N}$.

FAZENDA, I.

FERREIRA, E. S

FIORENTINI, D:

LORENZATO, S.

FREIRE, P.

FREIRE, P.

GIARDINETTO, J. R.B.

IMBERNÓN, F. $\quad$ Formação docente e profissional: formar-se para a

Formação docente e profissional: formar-se para
mudança e a incerteza. São Paulo: Cortez, 2000.

O Currículo Tradicional e a Educação Matemática

In: Educação Matemática em Revista. $\operatorname{SBEM}, \mathrm{n}^{\circ} 2$, ano 1,1994

IMENES, L. M. P
Um estudo sobre o fracasso do ensino e da aprendizagem da matemática. Rio Claro, IGCUNESP, 1989. Dis. de Mestrado.

\begin{tabular}{|c|c|}
\hline $\mathrm{R}$ & Básica \\
\hline $\mathrm{R}$ & Básica \\
\hline $\mathrm{R}$ & Básica \\
\hline $\mathrm{S}$ & Complementar \\
\hline D & Complementar \\
\hline D & Complementar \\
\hline $\mathrm{D}$ & Complementar \\
\hline $\mathrm{R}$ & Básica \\
\hline D & Complementar \\
\hline D & Complementar \\
\hline $\mathrm{D}$ & Complementar \\
\hline D & Básica \\
\hline $\mathrm{R}$ & Básica \\
\hline Q & Básica \\
\hline $\mathrm{S}$ & Complementar \\
\hline $\mathrm{S}$ & Complementar \\
\hline $\mathrm{S}$ & Complementar \\
\hline G & Complementar \\
\hline $\mathrm{R}$ & Complementar \\
\hline Q & Básica \\
\hline $\mathrm{R}$ & Complementar \\
\hline Q & Complementar \\
\hline $\mathrm{R}$ & Complementar \\
\hline$G$ & Complementar \\
\hline $\mathrm{D}$ & Básica \\
\hline $\mathrm{G}$ & Básica \\
\hline $\mathrm{D}$ & Complementar \\
\hline Q & Básica \\
\hline $\mathrm{D}$ & Complementar \\
\hline
\end{tabular}

Continuação 


\begin{tabular}{|c|c|c|c|}
\hline IMENES \& JAKUBOVIC. & $\begin{array}{l}\text { Matemática aplicada. (3 vol.) São Paulo: Moderna, } \\
1980 .\end{array}$ & $\mathrm{D}$ & Complementar \\
\hline $\begin{array}{l}\text { IMENES, L. M.; SANTOS, C. } \\
\text { H. }\end{array}$ & $\begin{array}{l}\text { Tangram - um antigo jogo chinês nas aulas de } \\
\text { matemática. Revista de Ensino de Ciências, } n^{\circ} 18 \text {, } \\
\text { agosto, } 1987 .\end{array}$ & Q & Complementar \\
\hline KLINE, M. & $\begin{array}{l}\text { O fracasso da matemática moderna. São Paulo: } \\
\text { IBRASA, } 1976 .\end{array}$ & Q & Complementar \\
\hline LIMA, E. L. & $\begin{array}{l}\text { Exame de Textos: Análise de Livros de } \\
\text { Matemática para o Ensino Médio. Rio de Janeiro: } \\
\text { SBM, 2001. (Coleção do professor de matemática; } \\
\text { 19). }\end{array}$ & $\mathrm{R}$ & Básica \\
\hline LORENZATO, S. & $\begin{array}{l}\text { Para aprender matemática. Campinas: Autores } \\
\text { Associados, 2006. (Coleção Formação de } \\
\text { professores). }\end{array}$ & $\mathrm{D}$ & Básica \\
\hline LORENZATO, S. & $\begin{array}{l}\text { O laboratório de ensino de Matemática na } \\
\text { formação de professores. Campinas: Autores } \\
\text { Associados, } 2006 \text {. }\end{array}$ & G & Básica \\
\hline MACHADO, N.J. & $\begin{array}{l}\text { Epistemologia e Didática: as concepções de } \\
\text { conhecimento e inteligência e a prática docente. } 6 \\
\text { ed. São Paulo: Cortez, } 2005 \text {. }\end{array}$ & G & Básica \\
\hline MACHADO, S. D. A. & $\begin{array}{l}\text { Educação Matemática: uma introdução, EDUC, } \\
\text { São Paulo, } 1999 .\end{array}$ & $\mathrm{N}$ & Complementar \\
\hline $\begin{array}{l}\text { MATOS, J. M. \& } \\
\text { SERRAZINA, M. L. }\end{array}$ & $\begin{array}{l}\text { Didáctica da Matemática. Lisboa: } \\
\text { Universidade Aberta, } 1996 .\end{array}$ & $\mathrm{D}$ & Complementar \\
\hline $\begin{array}{l}\text { MONTEIRO, A. \& JUNIOR, } \\
\text { G. P. }\end{array}$ & $\begin{array}{l}\text { A Matemática e os Temas Transversais. São } \\
\text { Paulo: Moderna, } 2001 .\end{array}$ & $\mathrm{D}$ & Complementar \\
\hline MORAIS FILHO, D. C. de. & $\begin{array}{l}\text { Um convite à matemática. Rio de Janeiro: SBM, } \\
\text { 2012. (Coleção do professor de matemática, 23). }\end{array}$ & $\mathrm{R}$ & Complementar \\
\hline MORETTO, P. V. & $\begin{array}{l}\text { Planejamento: planejando a educação para o } \\
\text { desenvolvimento de competências. 2. ed. } \\
\text { Petrópolis: Vozes, 2008. }\end{array}$ & $\mathrm{D}$ & Complementar \\
\hline $\begin{array}{l}\text { NOGUEIRA, C. M. \& BOTH } \\
\text { CARVALHO, N. T. }\end{array}$ & $\begin{array}{l}\text { Iniciação a pesquisa do ensino da matemática. } \\
\text { Pelotas: [s.n.], } 2007 .\end{array}$ & A & Básica \\
\hline $\begin{array}{l}\text { OLIVEIRA, H.; BROCARDO, } \\
\text { J. e PONTE, J. P. da. }\end{array}$ & $\begin{array}{l}\text { Investigações matemáticas na sala de aula. } \\
\text { Autentica, } 2003 \text {. }\end{array}$ & G & Complementar \\
\hline PAIS, L. C. & $\begin{array}{l}\text { Didática da Matemática: uma análise da influência } \\
\text { francesa. Belo Horizonte: Autêntica, } 2001 .\end{array}$ & $\begin{array}{l}\mathrm{N} \text { e S } \\
\mathrm{D} \text { e G }\end{array}$ & $\begin{array}{c}\text { Básica } \\
\text { Complementar }\end{array}$ \\
\hline PARRA, C. & Didática da Matemática. Artmed, 1996. & $\mathrm{~N}$ & Básica \\
\hline PARRA, C. \& SAIZ, I. (orgs.) & $\begin{array}{l}\text { Didática da matemática: reflexões } \\
\text { psicopedagógicas. Trad. Juan Acuña Llorens. Porto } \\
\text { Alegre: Artes Médicas,1996. }\end{array}$ & $\mathrm{D}$ e $\mathrm{S}$ & Básica \\
\hline PENIN, S. T. de S. & $\begin{array}{l}\text { A aula: espaço de conhecimento, lugar de cultura. } \\
\text { Campinas: Papirus, } 1994 .\end{array}$ & $\mathrm{D}$ & Complementar \\
\hline $\begin{array}{l}\text { PONTE, J. P. \& SERRAZINA, } \\
\text { M. L. }\end{array}$ & $\begin{array}{l}\text { Didática da Matemática do 1o Ciclo. Lisboa: } \\
\text { Universidade Aberta, } 2000 .\end{array}$ & $\mathrm{D}$ & Complementar \\
\hline TAHAN, M. & $\begin{array}{l}\text { Matemática divertida e curiosa. RJ: Ed Record, } \\
1991 .\end{array}$ & Q & Básica \\
\hline $\begin{array}{l}\text { TARDIFF, M.; LESSARD, C. } \\
\text { (Orgs.). }\end{array}$ & $\begin{array}{l}\text { O ofício de professor: história, perspectivas e } \\
\text { desafios internacionais. Tradução: Lucy Magalhães. } \\
\text { Petrópolis: Vozes, 2008. }\end{array}$ & $\mathrm{D}$ & Básica \\
\hline
\end{tabular}

FONTE: Ementa da disciplina Didática da Matemática dos cursos de Licenciatura em Matemática a Distância. Acesso em: Junho de 2017. Organizado pelas autoras.

Pela diversidade de obras elencadas é possível tecer algumas observações. Adotam-se uma variedade de obras, as quais nem sempre abordam as pesquisas em didática da matemática. Discutem Educação, Educação Matemática, Didática e são documentos norteadores oficiais Diretrizes Curriculares Nacionais para a Formação de Professores e Parâmetros Curriculares Nacionais, dentre outras. Não há consenso quanto a escolha delas para o desenvolvimento dos conteúdos na disciplina de Didática da Matemática. Essa escolha determina conteúdos e aspectos teóricos a serem considerados e reflete concepções assumidas sobre o papel e o 
significado da didática da matemática na formação inicial docente. Identificam-se preocupações com conhecimentos gerais do ensino, os quais a disciplina de Didática poderia abarcar.

Constata-se também, que os principais autores que discutem a Didática da Matemática na atualidade nem sempre são considerados. Apenas uma destas obras, de autoria de Pais (2001) é adotada em 04 dos cursos analisados, o que reflete uma inconstância na seleção e adoção de referenciais para a disciplina. São temas de grande relevância para a formação docente, mas uma seleção mais específica aprofundaria discussões emergentes do processo de ensino e de aprendizagem da Matemática, priorizando os saberes matemáticos pedagógicos.

A preparação do professor para o ensino da matemática reclama por estes saberes de modo a proporcionar melhores conhecimentos sobre a organização do ensino para a aprendizagem de conceitos matemáticos pelos alunos.

Quanto a uma possível forma de desenvolvimento dos conteúdos na disciplina, a diversidade de bibliografias conduz a se pensar em estudos, análises, reflexões, discussões, criações de situações didáticas ou construção de sequências didáticas. Possível também pensar em análises e discussões relacionadas aos documentos oficiais que norteiam a Educação e a formação de professores, mas estabelecendo conexão com os elementos essenciais e estruturantes da Didática da Matemática e com os conteúdos matemáticos.

Considerando-se as inúmeras referências apresentadas pelos cursos, como também a ausência delas, a forma adotada no desenvolvimento da disciplina Didática da Matemática, pode configurar-se pelo estudo isolado, exposição dos conteúdos, leituras e reprodução dos conhecimentos em avaliações na disciplina. Ou seja, assumindo forma expositiva e não apresentando elementos que a diferencie dos modelos tradicionais de ensino ou daqueles propostos por cursos presenciais de Licenciatura em Matemática.

Diante do que foi identificado nos documentos, apresentam-se, na sequência, algumas considerações sobre a disciplina Didática da Matemática nos cursos de Licenciatura em Matemática a Distância.

\section{Algumas considerações sobre a disciplina Didática da Matemática a partir da análise dos documentos dos cursos}

A análise proposta pelos pares dialéticos teoria-prática e conteúdo-forma realizada nos documentos dos 08 cursos de Licenciatura em Matemática a Distância buscava identificar os aspectos teóricos, práticos, conteúdos e forma considerados na disciplina Didática da Matemática. 
Quanto aos aspectos teóricos e práticos identificados nos documentos, percebe-se que a disciplina aborda noções de teorias em educação matemática, recursos metodológicos para o ensino, avaliação da aprendizagem em matemática, relação da teoria com a prática em matemática, materiais didáticos e paradidáticos. As práticas assumidas na disciplina em relação aos aspectos teóricos são reconhecidas pelo movimento no sentido de criar, planejar, realizar, gerir e avaliar situações didáticas para o ensino da matemática, construir projetos de pesquisa e realizar análises e discussões sobre eles, construir e aplicar projetos temáticos no campo do estágio, produzir projetos de ensino de matemática, selecionar e organizar conteúdos para o ensino, utilizar o laboratório de ensino para o desenvolvimento de situações didáticas, refletir e questionar sua própria prática e produzir materiais didáticos para o ensino de Matemática.

Se a disciplina antecede os estágios supervisionados, uma possibilidade é no sentido de que seus conhecimentos sejam aplicados neste contexto, possibilitando utilizar as sequências didáticas, os materiais didáticos e projetos elaborados pelo licenciando. No entanto, observa-se nas MC que em apenas 03 cursos (IES D, G e Q) ela antecede os estágios, em 02 (IES A e R) é oferecida após, em outro (IES S), está no mesmo período do estágio I e em outros 02 (IES C e N), está após o estágio I e no mesmo período do estágio II. Pressupõem-se que seus conhecimentos nem sempre são considerados durante a formação, ou seja, para a aplicação no estágio, mas para a futura carreira docente.

A intenção da formação também chamou atenção: formação para ser pesquisador em educação matemática (IES A), para ser pesquisador e professor (IES R) ou para o exercício da docência, seja na Educação Básica ou Superior (IES C, D, G, N, Q e S). Pelos documentos constata-se que a disciplina fornece elementos teóricos para que o licenciando se constitua tanto como professor ou pesquisador e constituir-se professor inclui ser um constante pesquisador, mas isso não necessariamente é o foco da disciplina nos cursos analisados.

Outra constatação: dos 08 cursos analisados, somente 01 (IES G) insere a Atividade Prática como Componente Curricular (APCC) na disciplina Didática da Matemática. A inserção da APCC nas disciplinas específicas (ou unidades curriculares teóricas de cunho científico) solicita que estas sejam pensadas nos meandros da prática. Logo, inserida na disciplina Didática da Matemática, reclama seu aspecto prático. Ou seja, que a prática desenvolvida na disciplina assegure o estabelecimento da relação teoria-prática no desenvolvimento dos conhecimentos necessários à formação do professor de Matemática. Neste sentido, assume-se que a prática adotada na disciplina em relação aos aspectos teóricos considerados precisa colocar o licenciando em movimento de análise e reflexão sobre o ensino e a aprendizagem da Matemática. 
Em relação aos conteúdos programáticos, os documentos revelam a abordagem de parte de um grande rol de conteúdos que a disciplina pode fornecer ao sujeito, adentrando, também, em questões gerais do ensino. Abordam conteúdos como planejamento, organização do ensino e da aprendizagem, métodos e estratégias de ensino, avaliação, dentre outros, estabelecendo relação com o conteúdo matemático. No entanto, percebe-se que não há consenso sobre os conteúdos da disciplina, variando de um curso para outro.

A forma adotada para o desenvolvimentos destes conteúdos revela-se quando propõe a realização de atividades de caráter científico, cultural e acadêmico, seminários, apresentações, exposições, participação em eventos científicos, monitorias, confecção de relatórios de pesquisas, realização de atividades presenciais e a distância, palestras, comunicações orais, estudo e a análise crítica de atividades e experiências de ensino da Matemática, seleção e organização de conteúdos matemáticos, diálogos, análises e produção de materiais para o ensino de Matemática. No entanto, de modo geral, a disciplina tem assumido forma expositiva para o desenvolvimento dos conteúdos programáticos e os licenciandos produzindo situações didáticas para apresentação aos colegas. Uma possível justificativa para o enfoque expositivo seria pela relação com a disciplina de Metodologia do Ensino da Matemática. Porém, identifica-se nestes cursos que esta disciplina ocorre em período anterior à disciplina Didática da Matemática (IES A e S), em período posterior (IES D) ou, não aparece no currículo da formação inicial (IES C, G, N, Q e R).

Destaca-se também, que na IES G se propõe o desenvolvimento de atividades da disciplina Didática da Matemática no Laboratório de Ensino da Matemática.

Sobre a bibliografia elencada nas Ementas da disciplina, identifica-se uma grande variedade apontando a inexistência de um consenso na seleção e adoção das mesmas.

Conclui-se que, é pertinente avançar nas discussões sobre a constituição da disciplina acadêmica Didática da Matemática, refletindo os avanços conquistados como ciência. Grandes pesquisas vêm sendo desenvolvidas por Almouloud (2007), D’Amore (2007), Espinosa (2011), Godino (2004), Pais (2015), Parra e Saiz (1996), Rico (1999), dentre outros e apontam importantes contribuições. Desconsiderá-las na disciplina corrobora com o entendimento de que a Didática é suficiente para a preparação do professor de Matemática.

\section{Considerações finais}

O estudo realizado objetivou identificar quais aspectos teóricos, práticos, conteúdos e forma são considerados na disciplina Didática da Matemática nos cursos de Licenciatura em 
Matemática a Distância e a análise documental de 26 dos 44 cursos encontrados no sitio do MEC, autorizados a funcionar em 2017, revelou sua presença em apenas 08 destes cursos.

Causa preocupação pois os conteúdos e aspectos teóricos da Didática da Matemática podem ou não estar sendo contemplados em outras disciplinas do currículo. Quanto aos aspectos práticos e forma não se reconhecem elementos que a diferenciem dos cursos presenciais.

Deste modo, destaca-se a necessidade de fomentar discussões sobre sua constituição como disciplina acadêmica, considerando a importância dos conhecimentos nesta área para a formação do professor e fortalecendo o significado social da atividade docente no contexto atual brasileiro.

\section{Referências}

BRASIL, Ministério da Educação e Cultura. Conselho Nacional de Educação. Câmara da Educação Básica. Resolução n. 2, de 30 de janeiro 2012. Diretrizes Curriculares Nacionais para o Ensino Médio, 2012.

COSTA, L. P. da. Algumas considerações acerca da Didática e da Educação Matemática na Educação Básica. Anais da I Jornada de Didática- O ensino como foco e I Fórum de professores de Didática do Estado do Paraná. UEM, 2013.

D’AMORE, B. Elementos de Didática da Matemática. Tradução: Maria Cristina Bonomi. São Paulo: Editora Livraria da Física, 2007.

ESPINOSA, A. J. Didáctica de la Matemática, Educación Matemática e Investigación. Revista Ciências em Foco. v.1, n. 4, 2011. Disponível em:

http://ojs.fe.unicamp.br/index.php/cef/article/view/4562. Acesso em: $10 \mathrm{dez} 2017$.

FIORENTINI, D.; LORENZATO, S. Investigação em educação matemática: percursos teóricos e metodológicos. $3^{\text {a }}$ ed. rev. Campinas, SP: Autores Associados, 2009.

GAMBOA, S. S. Teoria e da prática: uma relação dinâmica e contraditória. Anais do V Colóquio de Epistemologia da Educação Física. Maceió: Universidade Federal de Alagoas, 2010, p. 1-12. Disponível em: http://congressos.cbce.org.br/index.php/cepistef/v_cepistef/paper/viewFile/2644/1109. Acesso em 25 fev 2020.

KOPNIN, P. V. A Dialética como Lógica e Teoria do Conhecimento. Tradução: Paulo Bezerra. Rio de Janeiro, RJ: Editora Civilização Brasileira S.A., 1978.

LIBÂNEO, José Carlos. Didática e trabalho docente: a mediação didática do professor nas aulas. In: LIBÂNEO, José Carlos; SUANNO, Marilza Vanessa Rosa; LIMONTA, Sandra Valéria. Concepções e práticas de ensino num mundo em mudança. Diferentes olhares para a didática. Goiânia: PUC GO, 2011b. (p. 85-100). 
LIBÂNEO, J. C. Didática. 2a ed. São Paulo: Cortez, 2013.

MIORIN, V. M. F. Uma abordagem dialético-materialista para a organização do espaço. Revista do Programa de Pós-graduação em Geografia. V. 6. 1990. Disponível em: http://www.uel.br/revistas/uel/index.php/geografia/article/viewFile/9898/8705. Acesso em: 02 $\operatorname{dez} 2018$.

SILVA, D. S. A Constituição Docente em Matemática a Distância: Entre Saberes, Experiências e Narrativas. Jundiaí: Paco, 2017.

VÁZQUEZ, A. S. Filosofia da práxis. Tradução: María Encarnación Moya. $1^{\text {a }}$ ed. Buenos Aires: Consejo Latinoamericano de Ciencias Sociales - CLACSO, São Paulo: Expressão Popular, Brasil, 2007.

VIDIGAL, L.; DIAS, V. A. T.; FRANCO, S. A. P. A categoria dialética conteúdo e forma no interior da Pedagogia Histórico-crítica. Anais do XII EDUCERE - Congresso Nacional de Educação. Curitiba: Paraná, 2017. Disponível em:

https://educere.pucpr.br/p1/anais.html?tipo=\&titulo=A+CATEGORIA+DIAL\%C3\%89TICA $+\mathrm{CONTE} \% \mathrm{C} 3 \% 9 \mathrm{ADO}+\mathrm{E}+\mathrm{FORMA}+\mathrm{NO}+\mathrm{INTERIOR}+\mathrm{DA}+\mathrm{PEDAGOGIA+HIST} \% \mathrm{C} 3 \% 93 \mathrm{R}$ ICO-CR\%C3\%8DTICA\&edicao=\&autor=\&area. Acesso em: 25 dez 2018.

8. Apoio Financeiro
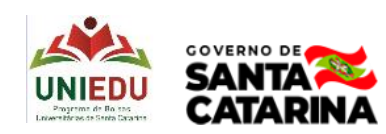